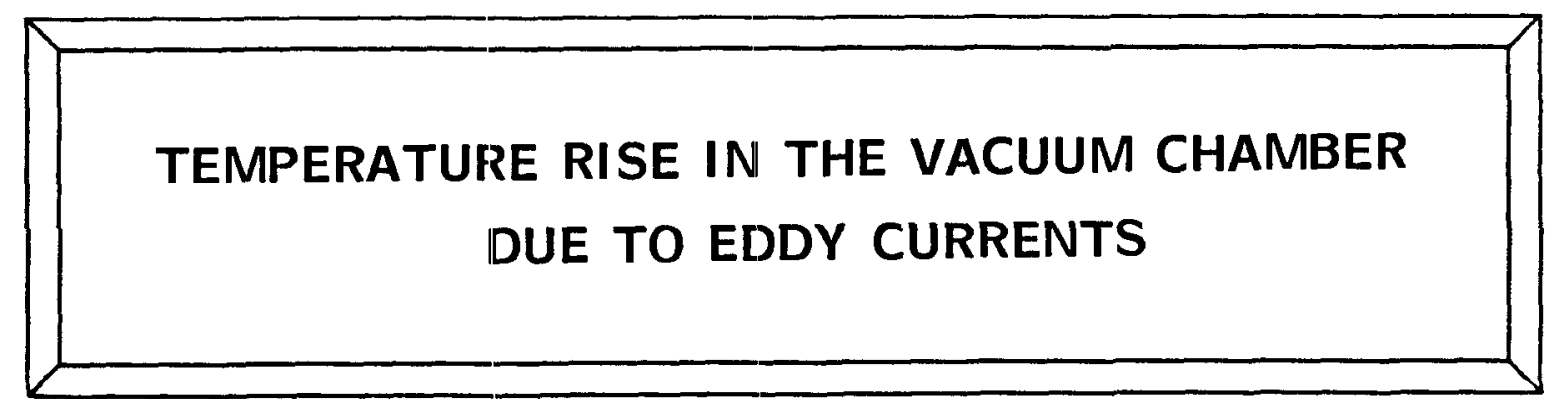

Booster Technical Note

No.50

G. H. Morgan

July 8, 1986

HIGH ENERGY FACILITIES

Brookhaven National Laboratory

Upton, N.Y. 11973 


\section{Temperature Rise in the Vacuum Chamber Due to Eddy Currents}

The cycle used for these calculations is that given in the Design Manual, Chapter 7 for proton operation, with no time between pulses, i.e., $100 \%$ duty cycle. In this cycle, the initial $\dot{B}$ is $1.468 \mathrm{~T} / \mathrm{sec}$, it rises to $9.5 \mathrm{~T} / \mathrm{sec}$ at $36 \mathrm{msec}$, and is constant to $62 \mathrm{msec}$, zero for $6 \mathrm{msec}$, then constant at $-8.27 \mathrm{~T} / \mathrm{sec}$ for $50 \mathrm{msec}$ and about zero for $15.3 \mathrm{msec}$. The $\mathrm{rms} \dot{\mathrm{B}}$ is $6.94 \mathrm{~T} / \mathrm{sec}$, the injection field $0.1563 \mathrm{~T}$ and the peak field is $0.545 \mathrm{~T}$.

The vacuum chamber is assumed to have a thickness $\mathrm{d}=1.5 \mathrm{~mm}, 304 \mathrm{~L}$ stainless-steel, 3.25 inch wide and 1.5 inch half-height at the center, tapering to 0.75 inch halfheight at the sides, as described in Tech. Note No. $4(1 / 28 / 86)$. The resistivity is $\rho_{\mathrm{S}}=0.809 \times 10^{-6}$ ohm-meter at $100^{\circ} \mathrm{C}$, the density is $\mathrm{g}=7.82 \mathrm{~g} / \mathrm{cm}^{3}$, the heat capacity $\mathrm{c}_{\mathrm{S}}=0.46 \mathrm{j} / \mathrm{g}^{\circ} \mathrm{C}$, and the thermal conductivity is $\mathrm{k}_{\mathrm{s}}=16.26 \mathrm{~W} / \mathrm{m}^{\circ} \mathrm{C}$. The chamber is assumed to be insulated with "Microtherm", a sheet material consisting of a powder enclosed by fiberglass cloth. The insulation package has a thickness $b=3.2 \mathrm{~mm}$ and has a thermal conductivity at $170^{\circ} \mathrm{C}$ of $\mathrm{k}_{\mathrm{i}}=0.021 \mathrm{~W} / \mathrm{m}^{\circ} \mathrm{C}$. A single layer is assumed.

If the thermal capacity of the insulation is ignored, the thermal time constant of the insulated stainless shell is $\tau=\mathrm{bdgc}_{\mathrm{s}} / \mathrm{k}_{\mathrm{i}}=8.2 \mathrm{sec}$. The heat capacity of the insulation will increase this. Since this time constant is much larger than the cycle time of $0.133 \mathrm{sec}$, heat flow will be almost constant once the steady state is acheived, and will be based on rms heat input. The steady-state temperature profile across the shell will take a considerably longer time to establish; the time constant for this is $\ell^{2} \rho_{s} c_{s} / k_{s}$ where $\ell$ is taken to be $1 / 4$ the chamber width, or about $5 \mathrm{~cm}$; this gives a time constant of 9 minutes. Fluctuations due to instantaneous heat input will be superimposed on the steady-state.

The exact solution of this problem can only be obtained by the numerical solution of the time-dependent differential equation, due to the way $\dot{B}$ is stated. However, an approximation can be obtained by first solving the steady-state problem with heat input equal to the rms value, then putting an upper bound on the ripple by using heat input proportional to peak $\dot{\mathrm{B}}^{2}$ with steady-state lateral loss and a lower bound with the same peak heat input but with lateral loss in proportion.

Since the transverse time constant is so large, it was first thought that transverse heat conduction could be neglected. If one does so, the peak steady-state temperature rise is given by $\Delta \mathrm{T}=\mathrm{bt}\left(\mathrm{x}_{\mathrm{e}} \dot{\mathrm{B}}\right)^{2} / \rho_{\mathrm{s}} \mathrm{k}_{\mathrm{i}}$, where $\mathrm{x}_{\mathrm{e}}$ is the chamber half-width, $8.18 \mathrm{~cm}$. The temperature rise obtained is $91^{\circ} \mathrm{C}$.

To determine the effect of transverse heat conduction, the chamber is approximated by a rectangle of half-wiclth $\mathrm{x}_{\mathrm{e}}$ and height $\mathrm{h}$. In the width, the heat generated per unit volume is $(x \dot{B})^{2} / \rho_{S}$, where $x$ is zero at the chamber center. The differential equation which applies is

$$
\mathrm{T}^{\prime \prime}+(\dot{\mathrm{B} x})^{2} / \rho_{\mathrm{s}} \mathrm{k}_{\mathrm{s}}-\mathrm{k}_{1}\left(\mathrm{~T}-\mathrm{T}_{\mathrm{a}}\right) /\left(\mathrm{btk}_{\mathrm{S}}\right)=0
$$

where prime denotes $d / d x$ and $T_{a}$ is ambient temperature. The solution is 


$$
\Delta \mathrm{T}=\dot{\mathrm{B}}^{2}\left(\mathrm{x}^{2}+2 / \mathrm{m}^{2}\right) /\left(\mathrm{m}^{2} \rho_{\mathrm{S}} \mathrm{k}_{\mathrm{s}}\right)+\mathrm{d} \cosh (\mathrm{mx})
$$

where $1 / \mathrm{m}$ is a characteristic distance; $\mathrm{m}=\left(\mathrm{k}_{1} /\left(\mathrm{btk}_{\mathrm{S}}\right)\right)^{0.5}$, and $\mathrm{d}$ is an unknown constant. On the side, the heat generated per unit volume is $\left(x_{e} \dot{B}\right)^{2} / \rho_{s}$ and the governing differential equation is the same, except that the generation term is independent of $x$. The solution is

$$
\Delta \mathrm{T}=\left(\dot{\mathrm{B}} \mathrm{e}_{\mathrm{e}} / \mathrm{m}\right)^{2} / \rho_{\mathrm{s}} \mathrm{k}_{\mathrm{s}}+\mathrm{e} \cosh (\mathrm{mu})
$$

where $e$ is an unknown constant and $u=x-x_{e}-h$. In these solutions, use has been made of the fact that $\mathrm{T}^{\prime}=0$ at the chamber center and also at the midplane on the side. The constants $d$ and $e$ are determined by requiring continuity of $T$ and $T^{\prime}$ at the corner between the width at $\mathrm{x}=\mathrm{x}_{\mathrm{e}}$ and the height.

$$
\begin{aligned}
& \mathrm{d}=-\mathrm{T}_{0}\left[\mathrm{mx} \mathrm{e}_{\mathrm{e}}+\sinh (\mathrm{mh}) \cosh (\mathrm{mh})\right] /\left[\sinh \left(\mathrm{mx}_{\mathrm{e}}\right)+\tanh (\mathrm{mh}) \cosh \left(m \mathrm{x}_{\mathrm{e}}\right)\right] \\
& \text { where } T_{0}=2 \dot{B}^{2} /\left(m^{4} \rho_{s} k_{s}\right) \\
& \mathrm{e}=\left[\mathrm{T}_{0}+\mathrm{d} \cosh \left(\mathrm{mx}_{\mathrm{e}}\right)\right] / \cosh (\mathrm{mh})
\end{aligned}
$$

Using the data given above, $1 / \mathrm{m}=6.096 \mathrm{~cm}, \mathrm{~T}_{0}=101.2^{\circ} \mathrm{C}, \mathrm{d}=-70.6^{\circ} \mathrm{C}$, and $\mathrm{e}=-$ $41.1^{\circ} \mathrm{C}$. On the midpane at $\mathrm{x}=\mathrm{x}$ en or $\mathrm{u}=0, \Delta \mathrm{T}=50.0^{\circ} \mathrm{C}$; at the edge, $\Delta \mathrm{T}=48.0^{\circ} \mathrm{C}$ and at the chamber center, $\Delta \mathrm{T}=30.6^{\circ} \mathrm{C}$. The effect of lateral heat transfer is thus much larger than expected, dropping the peak temperature rise $41^{\circ} \mathrm{C}$ and giving a temperature rise at the center $3 / 4$ of this, where zero would be expected if lateral conduction is neglected.

Finally, an upper bound for the peak instantaneous temperature can be approximated by replacing $B$ in eq.(2) by it's peak instantaneous value, leaving $d$ and $e$ as calculated for the steady-state. The result is $\Delta \mathrm{T}=129.6^{\circ} \mathrm{C}$ at the midplane. A lower bound is obtained by using peak $\dot{\mathrm{B}}$ everywhere; the result is $\Delta \mathrm{T}=93.7^{\circ} \mathrm{C}$. The average of these $\mathrm{t}$ wo is $\Delta \mathrm{T}=112^{\circ} \mathrm{C}$. 